\title{
PIBID: A AQUÍSIÇÃO DA COMPÊTÊNCIA LEITORA NOS ANOS INICIAIS DO ENSINO FUNDAMENTAL
}

\author{
Daiane Aquino dos Santos Sousa ${ }^{1}$ \\ Jessica Helena Baptista ${ }^{2}$ \\ Vera Lúcia Catoto Dias $^{3}$ \\ Anamaria da Silva Martin Gáscon Oliveira ${ }^{4}$
}

Resumo: Este trabalho é continuidade de pesquisa do Programa Institucional de Bolsa de Iniciação à Docência, PIBID, convênio firmado entre universidade comunitária e escola pública estadual, para formação inicial de professores na educação básica. O trabalho tem como objetivo investigar no desenvolvimento da competência leitora, as dimensões dos pressupostos teóricos presentes no processo. A pesquisa em educação do tipo estudo de caso etnográfico (ANDRÉ, 2005), no período de 2015-2016, realizada pela observação, em sala do $3^{\circ}$ ano do Ensino Fundamental I, em uma escola estadual, localizada no município de São José dos Campos, SP. A metodologia centrou-se inicialmente em pesquisa bibliográfica fundamentada em: Brasil (PCN, 1997); Smith (1999), Lerner (2002), dentre outros, seguida de pesquisa de campo. Os resultados indicaram que as atividades de leitura, desenvolvidas na escola pública contribuíram com o processo ensino e aprendizagem dos alunos, assim como na formação de futuras professoras participantes do PIBID.

Palavras-chave: Leitura; PIBID; Capacidade leitora; Escola pública.

\footnotetext{
1 Pedagogia/UNIVAP, Brasil. E-mail: naneaqn@hotmail.com.

2 Pedagogia/UNIVAP, Brasil. E-mail: jessica-hb@hotmail.com.

3 Pedagogia/UNIVAP, Brasil. E-mail: vcatoto@univap.br.

4 Pedagogia/UNIVAP, Brasil. E-mail: gascon@univap.br.
} 